\title{
A APRENDIZAGEM BASEADA NOS DESAFIOS DA EDUCAÇÃOO PROFISSIONAL DO PAÍS BASCO
}

\author{
Eugenio Astigarraga* \\ Agustin Agirre* *
}

* Doutor em Educação e Professor-

Pesquisador da Mondragon

Unibersitatea, Faculdade de

Humanidades e Ciências da

Educação. Eskoriatza, Guipúscoa,

País Basco. E-mail: eastigarraga@

mondragon.edu

** Técnico Superior em Automação da Tknika - Centro de Pesquisa e Inovação em Educação Profissional. Diretor da Área de Pesquisa de Métodos e Processos de Aprendizagem Tknika. Rentería Guipúscoa, País Basco. E-mail: aagirre@tknika.eus

Recebido para publicação em 20.07.2018

Aprovado em 16.10.2018

\section{Resumo}

Após uma breve contextualização do País Basco, este artigo descreve o modelo de formação ETHAZI (Ciclo de Alto Desempenho em basco), que vem sendo desenvolvido na Tknika - Centro de Pesquisa e Inovação em Educação Profissional - para responder às novas demandas que surgem no local de trabalho a partir da globalização e do aumento exponencial da tecnologia.

Palavras-chave: Educação profissional. Inovação educacional. Formação de professores. Competências específicas e transversais. País Basco.

\section{Introdução}

A Comunidade Autônoma do País Basco (CAPV) está localizada no norte da Espanha, na fronteira com o sudoeste do estado francês ${ }^{1}$. Esta Comunidade Autônoma é dirigida pelo Governo Basco, que, no contexto do Estado Autônomo, tem competências próprias (nem todas plenamente desenvolvidas) em comparação com as do Estado em diferentes âmbitos e, em particular, tanto no educativo como no trabalho.

Em relação ao tema abordado por este artigo, alguns dados e características atuais do País Basco são:

- Demograficamente, semelhante ao que acontece nos países mais desenvolvidos da Europa, é uma população que está progressivamente envelhecendo, com uma baixa taxa de natalidade que não atinge a taxa de reposição.

- As taxas de escolaridade são altas (Figura 1), enquanto a taxa de abandono escolar (Tabela 1) é baixa.

O nível educacional da população aumentou com o passar dos anos, o que se traduz em uma população ativa melhor educada (Figura 2) com o passar do tempo, em que o número de pessoas com baixa ou nenhuma qualificação diminui acentuadamente. 
Figura 1 - Taxa de escolaridade por faixas etárias

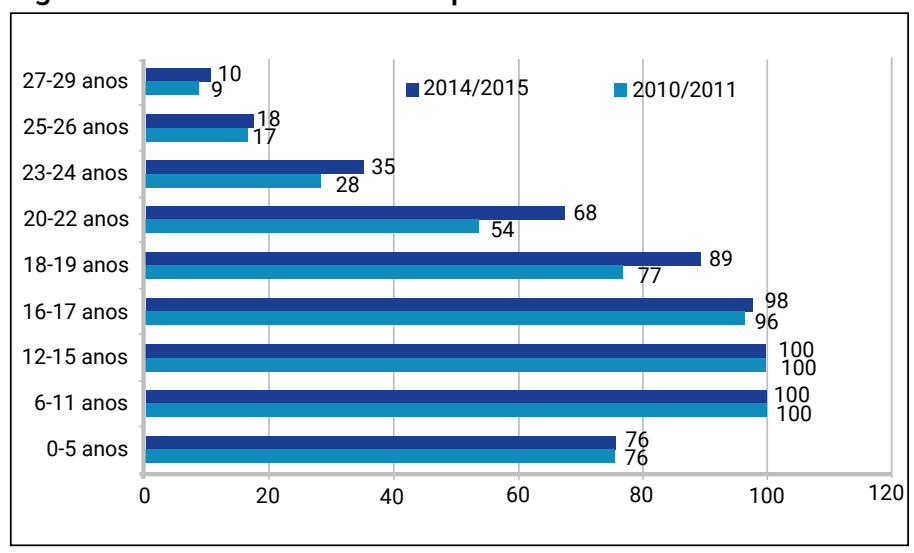

Fonte: Consejo Economico y Social Vasco (2018, p. 35).
Tabela 1 - Taxa de abandono escolar precoce

\begin{tabular}{|l|l|l|l|}
\hline \multirow{2}{*}{} & \multicolumn{3}{|c|}{$\mathbf{2 0 1 4}$} \\
\cline { 2 - 4 } & Total & Mulheres & Homens \\
\hline UE 28 & 11,1 & 9,5 & 12,7 \\
\hline Suécia & 6,7 & 6,0 & 7,3 \\
\hline C. A. de Euskadi & 7,2 & 6,6 & 7,7 \\
\hline Dinamarca & 7,7 & 6,0 & 9,3 \\
\hline França & 8,5 & 7,4 & 9,5 \\
\hline Países Baixos & 8,6 & 6,8 & 10,3 \\
\hline Finlândia & 9,5 & 7,2 & 11,9 \\
\hline Alemanha & 9,5 & 8,9 & 10,0 \\
\hline Reino Unido & 11,8 & 10,7 & 12,8 \\
\hline Espanha & 21,9 & 18,1 & 25,6 \\
\hline
\end{tabular}

Fonte: Consejo Economico y Social Vasco (2018, p. 34).

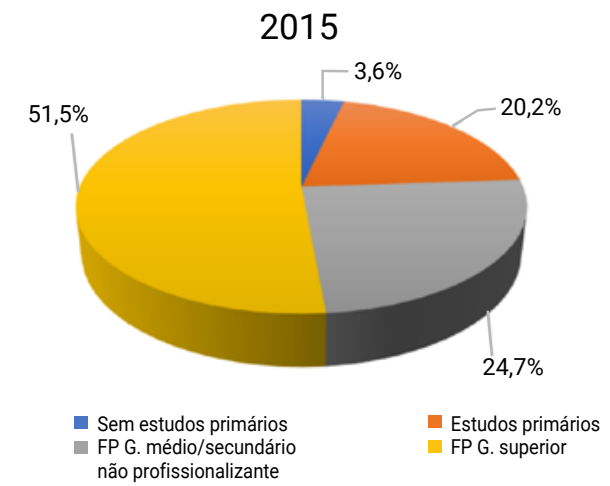

- Sem estudos primários não profissionalizante
Figura 2 - População ativa por nível de formação
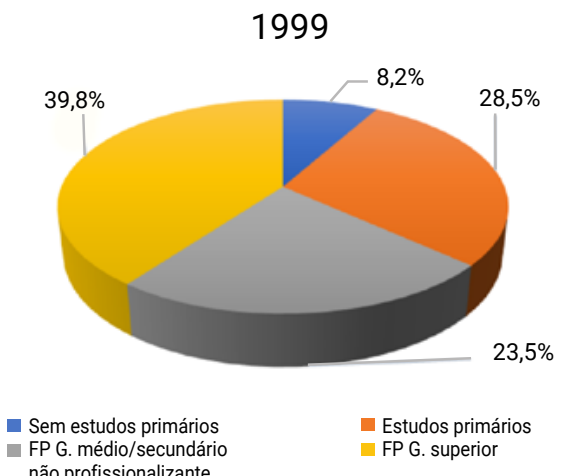

não profissionalizante

Fonte: Elaboração própria (ADEGI, 2016, p. 2).

- A taxa de desemprego (Tabela 2) dobrou desde uma década atrás, e, apesar de nos anos anteriores ter ficado acima dos 16,5\%, em 2016, foi de mais de $12 \%$ e espera-se que até o fim do ano esteja em torno de 10\%. Os jovens têm sido, em geral, os que mais sofrem com os efeitos do desemprego e, entre eles, inicialmente as mulheres, embora no início desta década as tabelas tenham começado a mudar.

Tabela 2 - Taxas de desemprego (total e jovens - por gênero) na CAPV

\begin{tabular}{|l|l|l|l|l|l|l|l|l|l|}
\hline & 2008 & 2009 & 2010 & 2011 & 2012 & 2013 & 2014 & 2015 & 2016 \\
\hline População total & 6,6 & 11,3 & 10,7 & 12,4 & 15,6 & 16,6 & 16,3 & 14,8 & 12,6 \\
\hline Jovens (16-34 anos) & 10,0 & 16,9 & 17,4 & 19,0 & 23,7 & 25,6 & 24,9 & 22,8 & 21,2 \\
\hline Homens & 9,5 & 17,7 & 17,1 & 18,6 & 24,9 & 26,6 & 25,7 & 23,9 & 20,6 \\
\hline Mulheres & 10,5 & 15,9 & 17,6 & 19,5 & 22,3 & 24,4 & 24,1 & 21,7 & 21,8 \\
\hline
\end{tabular}

Fuente: Consejo Economico y Social Vasco (2018, p. 53). 
- Do ponto de vista da atividade laboral, os serviços estão se consolidando como a principal fonte de emprego (Figura 3), e, embora a indústria recue no século 21 , seu peso continua sendo mais alto na CAPV do que no conjunto dos 28 países da União Europeia (UE28), visto que a participação da indústria no Produto Interno Bruto (PIB) é 4,4 pontos percentuais superior à da UE28 (CONSEJO ECONOMICO Y SOCIAL VASCO, 2018, p. 83-84).

Figura 3 - Evolução da população ocupada por setores de atividade (CAPV)

2000

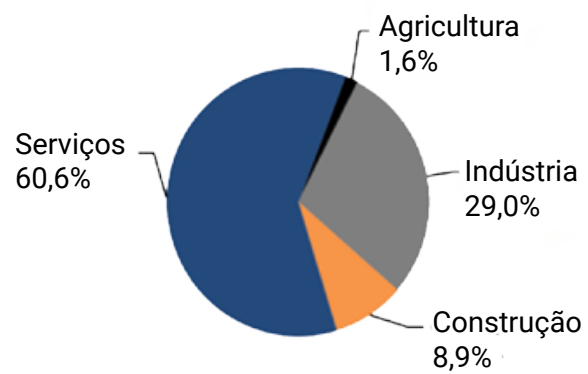

2016

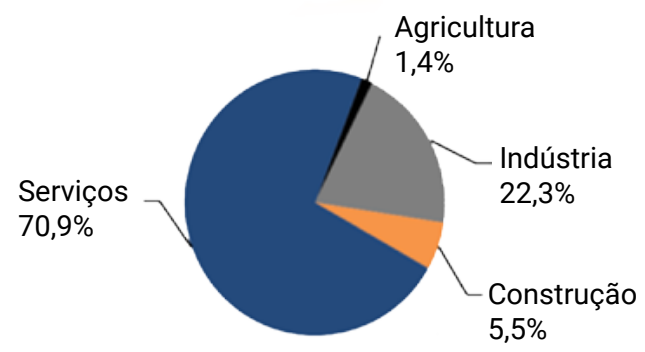

Fonte: Consejo Economico y Social Vasco (2018, p. 83) 34)

- $\quad 0$ apoio às empresas - em particular, às pequenas e médias empresas (PME) -, para a melhoria do tecido produtivo e da competitividade, baseia-se no apoio à tríade Investigação+Desenvolvimento+Inovação $(|+D+|)$, a qual permite que - País Basco esteja localizado em uma boa posição no domínio europeu da inovação (Figura 4).

Figura 4 - Índice europeu de inovação por regiões

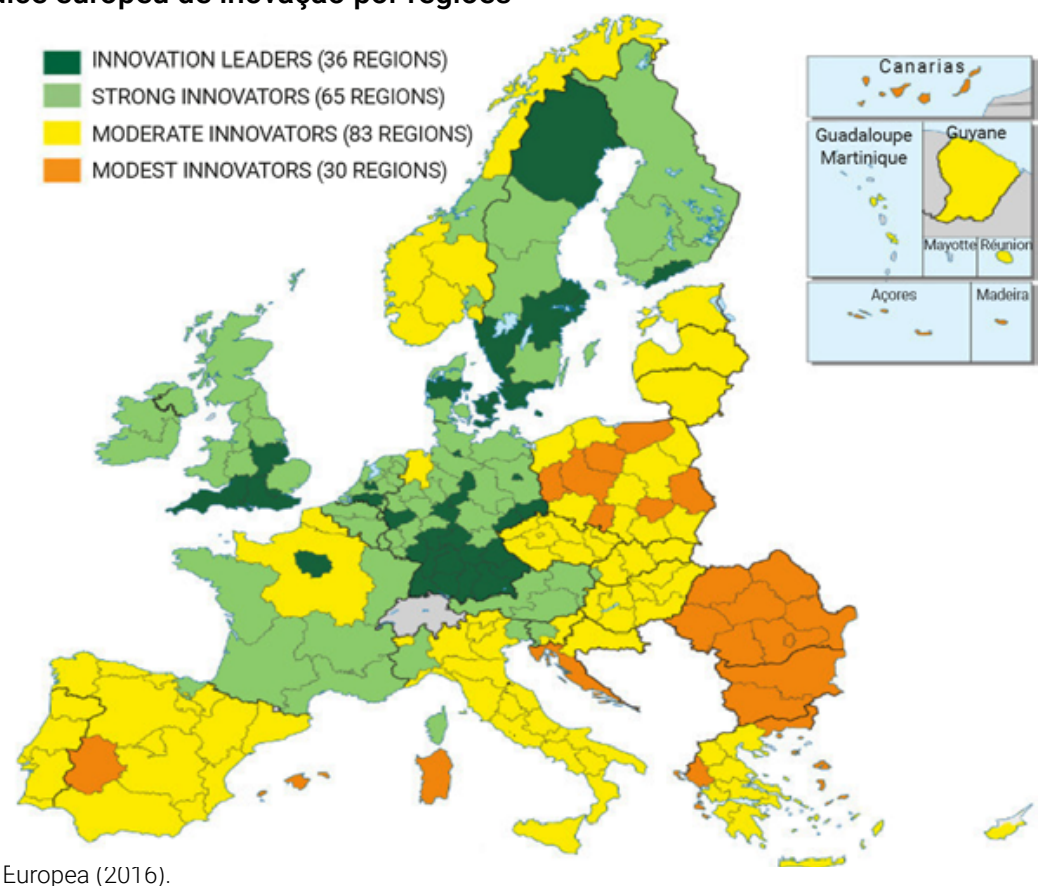

Fonte: Comisión Europea (2U16). 
O atual contexto de trabalho, embora seja definido e/ou caracterizado pela chamada Quarta Revolução Industrial, faz parte de uma dinâmica mais ampla e complexa, que apresenta uma nova sociedade baseada em informação, big data, robótica e inteligência artificial, o que permite vislumbrar que:

$O$ século XXI não é uma continuação do século $X X$, mas um conceito novo e muito diferente. Nesta época tudo está conectado com tudo. Isso exige novas estratégias e formas de pensar para enfrentar os grandes problemas e desafios da humanidade (MENÉNDEZ VELÁZQUEZ, 2017, p. 268).

\section{Tknika: Centro de Pesquisa e Inovação Aplicada da Educação Profissional do País Basco}

Tknika é o Centro de Pesquisa e Inovação Aplicada da Educação Profissional (EP) do País Basco, e foi criado pelo Decreto 39/2005. Desde então, e impulsionado pelo Vice-Conselho de Educação Profissional do Departamento de Educação do Governo Basco, tendo como principais vetores de atuação a pesquisa e a inovação aplicadas ao mundo da EP.

A instituição torna-se, assim, um elemento dinâmico que, por meio da vigilância e da inteligência competitiva, possibilita a transferência de produtos e serviços inovadores e de alto valor agregado para os centros EP da CAPV e, a partir deles, para o setor empresarial. Para isso, atualmente, está organizado em seis áreas principais: Inovação aplicada no domínio da EP; Melhoria contínua; Pesquisa de Métodos e Processos de Aprendizagem; Empreendedorismo e Gestão de Mudanças; Internacionalização no campo da EP; Sustentabilidade (última área incorporada).

A Tknika desenvolve o seu trabalho em rede, contando com o envolvimento dos Centros e professores ${ }^{2}$ de EP do País Basco, tomando como ponto de partida a Comunidade Autônoma e abrindo e colaborando com centros, organizações e instituições de todo o mundo, o que Ihe valeu o nome de Centro UNEVOC no ano letivo 2016-17.

Nesse contexto, no ano letivo 2009-1033, e dentro da Área de Pesquisa Métodos e Processos de Aprendizagem, começa-se a trabalhar em um novo olhar sobre o que acontece nas salas de aula de Educação Profissional, levando em consideração o que está acontecendo não só no nível social, mas principalmente no nível empresarial. Nesse sentido, alguns pontos-chave subjacentes a essa reflexão são os seguintes:

1. As empresas estão mudando sua forma de fazer as coisas, estão entrando em um novo paradigma produtivo-trabalhista e vão exigir pessoas com novas competências e habilidades, por isso, é necessário alterar as propostas de formação oferecidas pelos Centros. 
2. O professor não pode mais trabalhar sozinho, sendo cada vez mais necessário que se trabalhe em equipe. A mudança educacional e a melhoria na qualidade da educação só ocorrerão se o grupo de professores de um $\mathrm{Ciclo}^{4}-\mathrm{e}$, em muitos aspectos, aqueles do Centro como um todo - funcionar como uma equipe.

3. A Educação Profissional tem que desenvolver as competências técnicas específicas do ambiente de trabalho correspondente, mas, juntamente com elas, exigem-se mais e mais competências "brandas", como responsabilidade, trabalho em equipe e resolução de problemas.

4. O desenvolvimento integrado das competências requeridas exige a superação da divisão entre teoria e prática, abordando situações e problemas reais a partir de abordagens inter e transdisciplinares.

5. É necessário passar de modelos centrados no ensino para modelos que enfatizem a aprendizagem; assim, também é necessário mudar tanto o papel do aluno - mais ativo e responsável pela sua própria aprendizagem; quanto o do professor - mais orientado a estimular e favorecer a aprendizagem do que apenas transmitir conteúdo.

É necessário
passar de modelos
centrados no
ensino para
modelos que
enfatizem a
aprendizagem

6. Neste contexto, a aprendizagem dos alunos, além de ser ativa - na qual desempenham um papel de protagonistas - deve também ser uma aprendizagem colaborativa/cooperativa, destinada a resolver problemas e situações semelhantes aos encontrados no local de trabalho para o qual está se preparando.

7. O mundo atual e, em particular, o mundo em que a vida será desenvolvida, será um mundo digital, portanto, deve-se ser competente para desenvolver-se como cidadão digital, aplicando princípios e valores éticos em relação a todos esses fatores.

8. Neste contexto de automação progressiva, aspectos como criatividade e empreendedorismo serão aqueles que possibilitarão manter a competitividade de pessoas e empresas, melhorando, assim, a qualidade de vida da sociedade.

9. Todos os itens mencionados exigem novas formas de organização dos Centros, das distribuições de tempo, da alocação de tarefas, dos espaços.

10. Ao mesmo tempo em que os vários aspectos mencionados estão sendo alterados e/ou mudando seu foco, é essencial repensar, também, a avaliação, caminhando para uma nova abordagem de natureza mais formativa e evolutiva, na qual o aluno tem um novo protagonismo.

\subsection{Abordagem do modelo ETHAZI (Ciclos de Alto Desempenho)}

Como afirmado em Astigarraga, Agirre y Carrera (2017), a análise do escopo das práticas educacionais e das tendências existentes levou a Tknika a definir o modelo ETHAZI para a EP do País Basco. Este modelo, ainda em evolução, desenvolvimento e crescimento, é representado em forma gráfica (Figura 5), com base nos seguintes elementos: 


\section{a) 0 contexto ou ecossistema}

Figura 5 - Representação gráfica do modelo ETHAZI

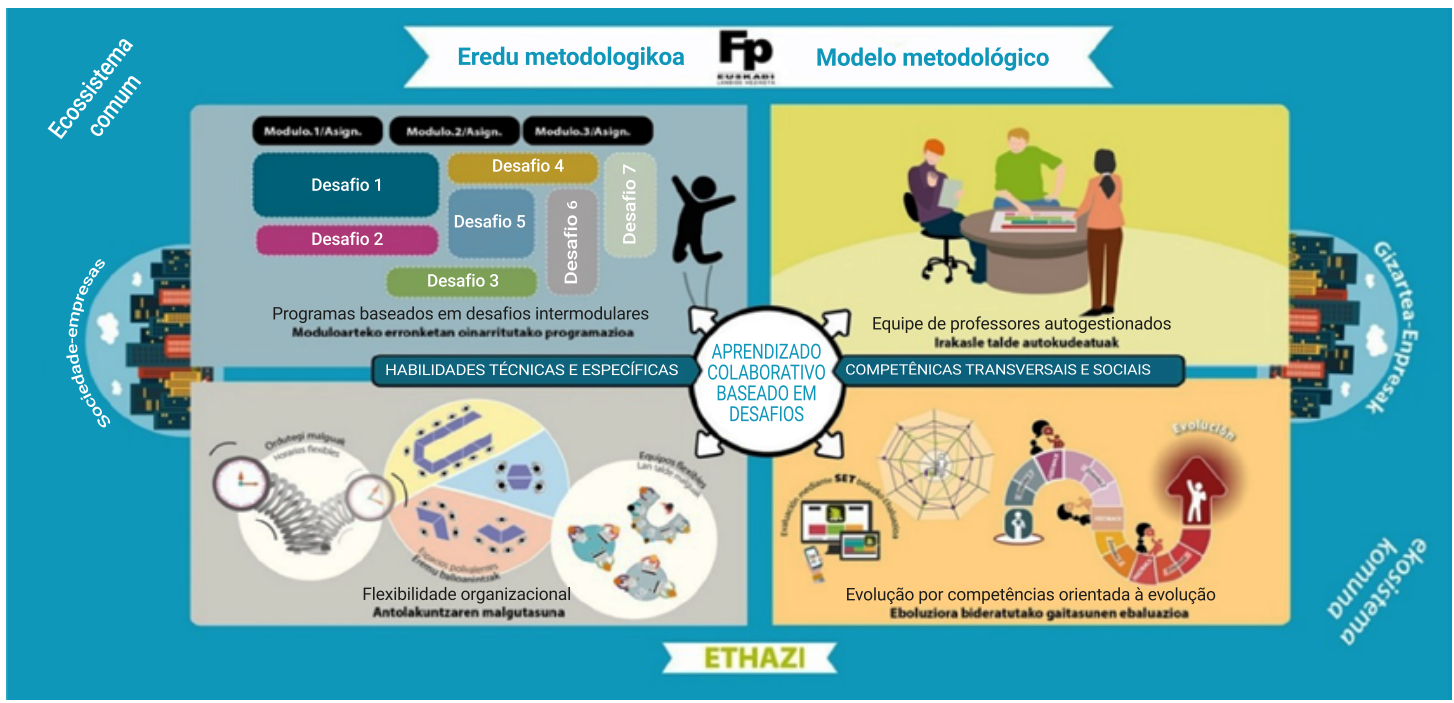

Fonte: Tknika

A atividade educativa e, em particular, a EP, está inserida em um contexto social e laboral que tem suas particularidades (história, características, evolução, relações) e necessidades que devem ser respondidas por estas propostas de formação. 0 contexto ou ecossistema - no qual tanto as empresas quanto a sociedade estão localizadas - tem sido caracterizado, nos últimos anos, pela sua globalização, digitalização e hipertecnologização.

Resumidamente, algumas das principais características que o mundo do trabalho está apresentando são:

- Mudanças nas habilidades exigidas nos empregos a partir de: novos trabalhos e profissões, que exigirão novas competências; modificação das habilidades necessárias em praticamente todas as ocupações devido à influência da tecnologia; desaparecimento de profissões, o que tornará obsoletas as habilidades a elas associadas.

- Polarização nos empregos, evidenciando sua diminuição em níveis de baixa-média complexidade, o que parece indicar maiores dificuldades para a automação dos empregos nos dois extremos e, em particular, naquelas ocupações que exigem alta e média habilidade (AUTOR; DORN, 2013; CEDEFOP, 2018; ELLIOT, 2017; LOSKHAREVA et al., 2018).

- Maior demanda por qualificação, a qual se traduz em um nível de competência mais amplo de pessoas, que integra habilidades técnicas ou profissionais com as competências transversais ou competências do século XXI (ASTIGARRAGA; 
AGIRRE Y CARRERA, 2017; BANCO INTERAMERICANO DE DESARROLLO, 2016; COMISIÓN EUROPEA, 2015; LOSHKAREVA et al., 2018; WORLD ECONOMIC FORUM, 2015, 2016).

- Importância, por não poder ser facilmente automatizada, de competências socioemocionais (ORGANIZACIÓN PARA LA COOPERACIÓN Y EL DESARROLLO ECONÓMICO, 2015) e, em menor medida, das habilidades cognitivas principalmente as de alto nível - comparadas àquelas de natureza psicomotora, o que implicará trabalhar com - e no controle de - robôs e novas máquinas inteligentes em áreas como: cibereconomia, economia criativa, serviços voltados para as pessoas, cuidado com o meio ambiente, novas tecnologias emergentes... (LOSHKAREVA et al., 2018).

\section{b) Aprendizagem Colaborativa Baseada em Desafios (ACBR)}

Atualmente, existem múltiplas abordagens e propostas de mudança educacional baseadas em diferentes estratégias e/ou metodologias, sendo as que têm maior potencial "aquelas que são especialmente baseadas em pesquisa e trabalho colaborativo (dado que) essas abordagens preparam os alunos explicitamente para o aprendizado futuro" (ORGANIZACIÓN PARA LA COOPERACIÓN Y EL DESARROLLO ECONÓMICO, 2013, p. 88). Como exemplo, e sem pretender ser exaustivo, pode-se mencionar: Aprendizagem Baseada em Projetos; Aprendizagem Baseada em Problemas Orientada a Projetos; Aprendizagem Baseada em Perguntas; Aprendizagem Baseada em Pesquisa; Aprendizagem Baseada em Fenômenos; Aprendizagem Baseada em Evento; Aprendizagem Baseada no Trabalho; Aprendizagem Baseada em Desafios e outras.

Dentro dessas estratégias metodológicas, é possível, por sua vez, encontrar diferentes propostas metodológicas (Método de Projetos, Método de Análise, Simulações, Estudos de Caso, Oficinas, Design Thinking...) $)^{5}$, que não são mutuamente exclusivas, podendo usar muitas delas em conjunto.

$\mathrm{Na}$ Tknika, sabendo que sob o nome de Aprendizagem Baseada em Desafios existem diferentes propostas ${ }^{6}$, propõe-se uma abordagem ampla, flexível e até mesmo eclética, nos moldes indicados por Barron e Darling-Hammond (2010, p. 231), quando eles reconhecem sua importância e validade, pois "permitem a comunicação, a cooperação, a criatividade e o pensamento profundo". No entanto, eles também enfatizam a dificuldade de aplicá-los, uma vez que:

dependem em grande parte dos conhecimentos e das habilidades dos professores que os aplicam... Os professores precisam de tempo e de uma comunidade que apoie sua capacidade de organizar o trabalho por projetos de maneira sustentável. São necessárias sólidas habilidades pedagógicas para administrar projetos de longo prazo em sala de aula, sem perder de vista o fato de que o objetivo é 'fazer-se entender' e não 'fazer por fazer' (BARRON; DARLING-HAMMOND, 2010, p. 231). 
Nesse sentido, a ACBR - sempre aberta a concretizações adicionais e específicas, tem as seguintes características principais:

\section{- Aprendizagem colaborativa}

Como afirmado em Astigarraga, Agirre y Carrera (2017, p. 74), a Aprendizagem Colaborativa implica (BARKLEY; CROSS; MAJOR, 2012; INSTITUTO TECNOLÓGICO Y DE ESTUDIOS SUPERIORES DE MONTERREY, 1999) contar com:

- Trabalho em pequenas equipes (geralmente, heterogêneas).

- Interdependência positiva entre os membros de cada equipe, e, às vezes, em função da proposta que está sendo desenvolvida entre as diferentes equipes.

- Responsabilidade e reflexão individual e em grupo ao longo do desenvolvimento da proposta de trabalho.

- Interação simultânea entre os componentes da equipe, mas também com os docentes.

- Implementação de habilidades sociais nas interações em equipe, bem como nas relações com docentes e pessoas externas (empresas, instituições etc.).

\section{- Aprendizagem Baseada em Desafios}

O Desafıo é uma situação-problema que, em geral, tem as seguintes características 7 :

- $\quad$ É uma situação - tão real quanto possível - do contexto de trabalho para o qual está sendo formada.

- Exige, portanto, a análise do ambiente em que é apresentado como próximo das pessoas que devem enfrentá-lo.

- $\quad$ Pretende-se ter mais de uma solução, a fim de possibilitar espaços/situações de pensamento divergente e criativo.

- Envolve, portanto, análise e reflexão sobre a situação (contexto, antecedentes, parâmetros e condições e identificação de alternativas).

- $\quad$ Nesse sentido, a proposta feita pode ser difusa, obscura, de forma que sua concretização fique nas mãos das equipes de trabalho.

- Como já foi dito, implica a colaboração e o trabalho em equipe dos alunos.

- Baseia-se e requer a ativação de conteúdo e conhecimentos previamente desenvolvidos.

- No entanto, não é uma mera aplicação de conteúdos e conhecimentos prévios, mas envolve trabalho sobre novos conteúdos e o desenvolvimento de novos conhecimentos.

- Baseia-se, portanto, na ação, direcionada pela busca, análise e processamento de novas informações, visando alcançar os resultados de aprendizagem (técnicos e transversais) previamente definidos. 
- O resultado destes processos gera evidências e produtos (relatórios, protótipos, planos, infográficos, vídeos, apresentações, mapas conceituais, cronogramas) que permitem monitorar a evolução, bem como a avaliação do desenvolvimento dos resultados de aprendizagem (técnicos e transversais) previamente definidos.

- De maneira genérica, embora cada desafio possa ter suas particularidades, a Figura 6 mostra os principais passos ou etapas acarretados pela identificação, apropriação, desenvolvimento e avaliação de um desafio.

Figura 6 - Fases no desenvolvimento de um desafio

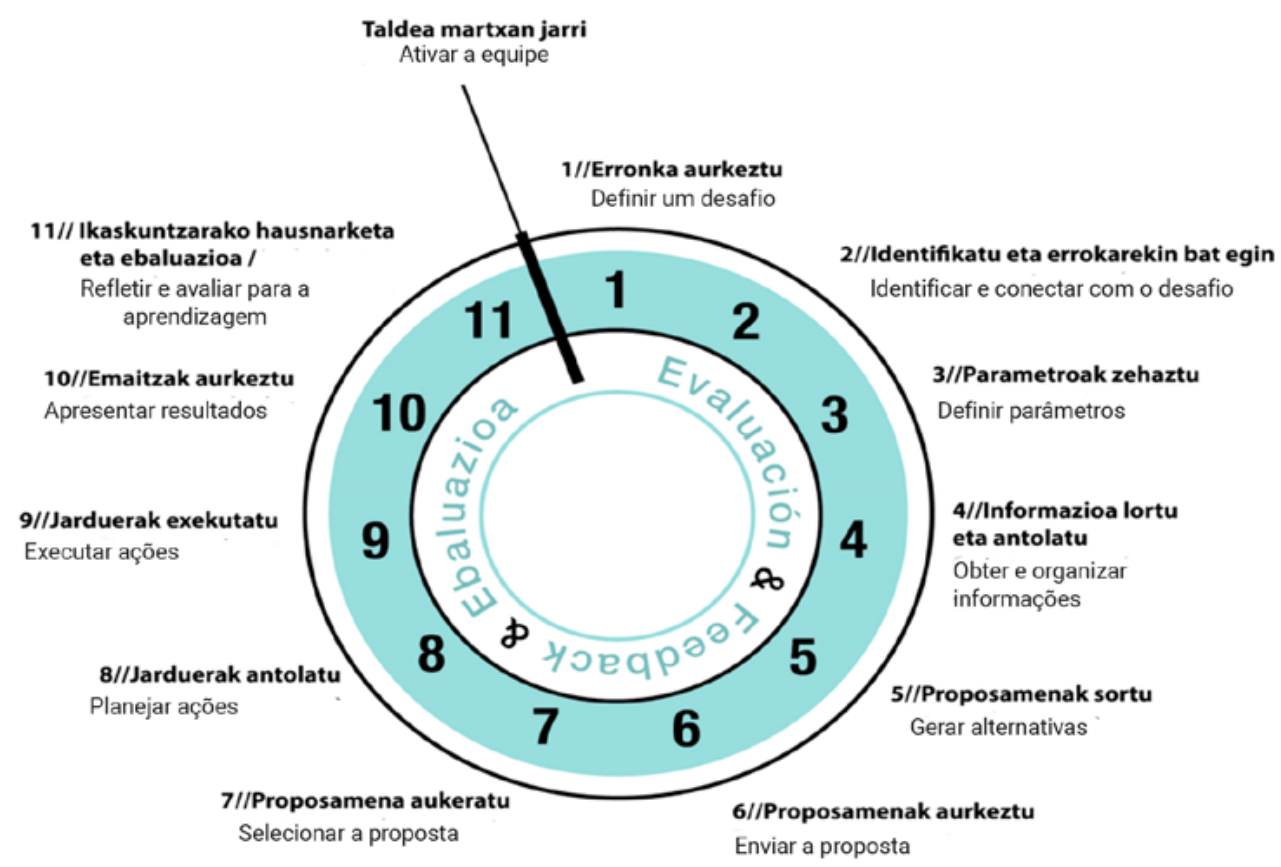

Fonte: Tknika.

\section{- Orientado ao desenvolvimento de competências técnicas e transversais}

- Após a criação do Marco Europeu de Qualificações (UNIÓN EUROPEA, 2009), foi ampliada na EP europeia a definição de currículos baseados nos resultados de aprendizagem (CEDEFOP, 2009, 2010, 2016, 2017). No contexto espanhol, os Resultados de Aprendizagem (RA) relacionados com as competências técnicas estão claramente definidos nos Decretos Reais correspondentes, emitidos pelo Ministério da Educação; talvez menos claramente, também nestes Decretos Reais há referência aos RA relacionados às competências transversais. Tudo isso pode ser encontrado no site do Instituto Basco do Conhecimento - Ezagutzaren Euskal Institutua. 
É possível observar que, atualmente, os RA relacionados às competências transversais estão assumindo um novo papel. Isso se deve, principalmente, a uma dupla consideração; por um lado, o aumento da disponibilidade de conteúdo, facilmente acessível a partir de praticamente qualquer lugar, a qualquer momento e a um custo muito baixo; por outro lado, e relacionado ao anterior, à percepção de que esse tipo de competência tem um tempo de vida mais longo e, ao mesmo tempo, menos fácil de ser automatizado.

No contexto do desenvolvimento do modelo ETHAZI, da Tknika, quatro grupos de competências transversais são propostos aos Centros (Figura 7) para o seu desenvolvimento nos diferentes desafios.

Figura 7 - Competências transversais selecionadas para seu desenvolvimento na EP da CAPV
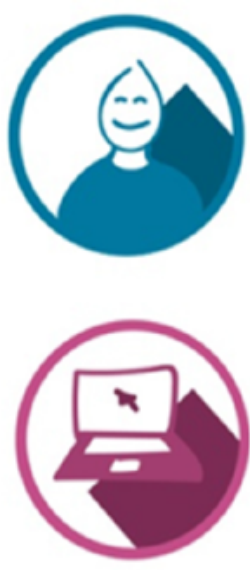

PESSOAL

Autonomia Implicação Iniciativa empreendedora
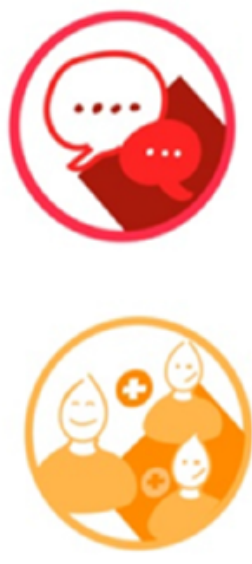

COMUNICAÇÃO

Comunicação oral

Comunicação escrita

COLABORATIVO

Trabalho em equipe

Solução de problemas

Tomada de decisões

Fonte: Tknika.

No âmbito produtivo, a importância dessas competências transversais também se evidencia no contexto próximo, que, como se vê, está frequentemente relacionado às atitudes, ao envolvimento e aos modos de agir em relação ao contexto de trabalho. Prova disso são os resultados obtidos pela Confebask em uma pesquisa respondida por cerca de 1.000 empresas do País Basco neste ano, em que o principal aspecto levado em consideração pelas empresas bascas no momento da contratação está sob a epígrafe: Atitude / Disposição / Interesse, seguido da Formação do(a) candidato(a) (Figura 8).

Dentro desse escopo de natureza transversal, diversas são as características sublinhadas, entre elas: responsabilidade, atitude proativa, adaptabilidade, autonomia e outras (Figura 9). 
Figura 8 - Aspectos prioritários para contratação nas empresas bascas

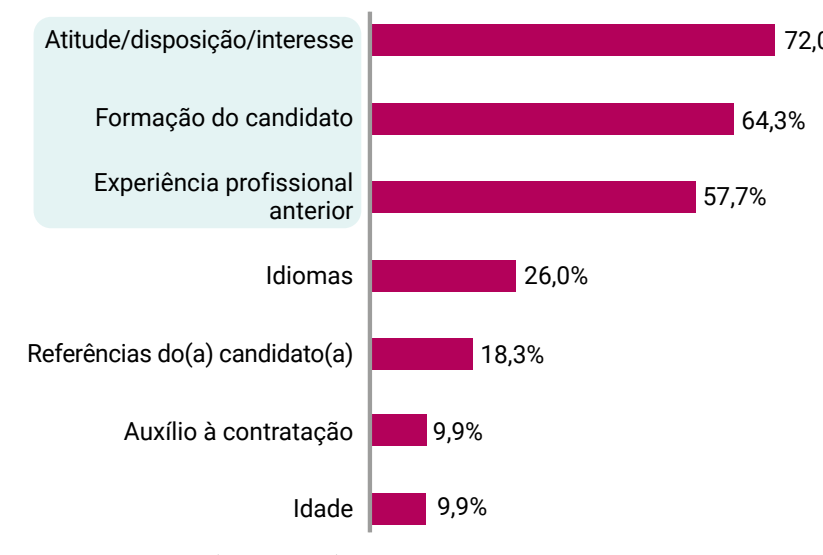

Figura 9 - Competências transversais mais valorizadas para contratação nas empresas bascas

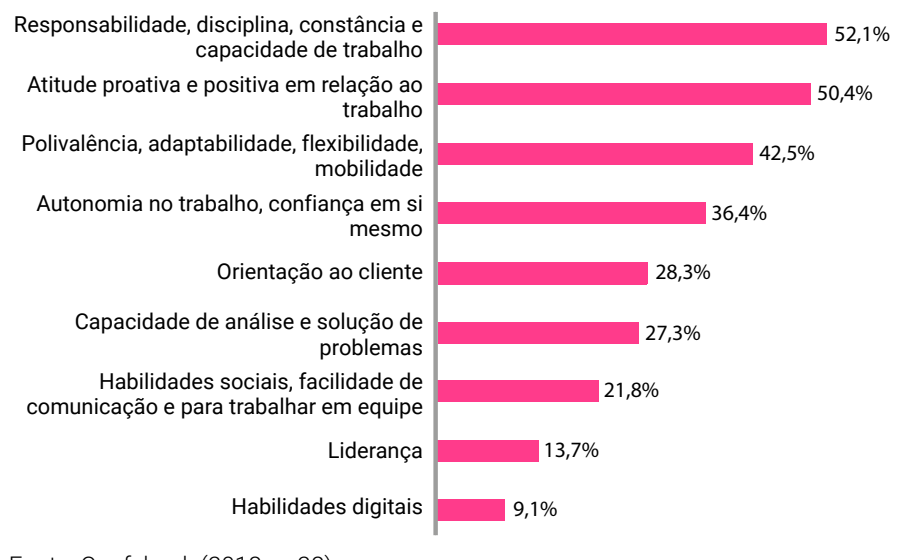

Fonte: Confebask (2018, p. 28).

Dessa forma, o modelo de EP que está sendo promovido no País Basco - sustentado na Aprendizagem Colaborativa Baseada em Desafios para o desenvolvimento de competências técnicas e transversais - está estruturado em torno de quatro eixos:

\section{Programação baseada em desafios}

Como já foi apontado, pretende-se que a programação como um todo seja desenhada e estruturada com base no desenvolvimento de diferentes desafios. Dado que as atividades e situações que os estudantes irão encontrar no local de trabalho serão de caráter interdisciplinar - ao mesmo tempo que de diferentes tipos - a identificação e o desenho dos desafios intermodulares (inter/transdisciplinares) desenvolvidos e resolvidos serão promovidos com o uso combinado de diferentes metodologias, que requerem trabalho individual e em grupo.

\section{Programações desenvolvidas pelas Equipes Docentes do Ciclo (EDC)}

A atual perspectiva educacional afeta cada vez mais a importância do trabalho em equipe dos docentes, superando o individualismo e o exercício da função docente isolada. Portanto, é necessário - nessa mudança de paradigma educacional - prover autonomia e responsabilidade às equipes docentes, para que projetem de forma compartilhada e consensual os diferentes desafios, organizem seus espaços e tempos, distribuam tarefas e responsabilidades para o interior da equipe docente, e constituam-se com referência ao trabalho em equipe que será exigido dos alunos. Como é evidente, os EDC são o elemento central e essencial para o desenvolvimento desse modelo, a partir de sua liderança, empoderamento e formação. 


\section{Flexibilidade organizacional}

Os aspectos mencionados, por sua vez, exigem novas formas de organização dentro dos Centros $^{8}$. 0 trabalho em equipe dos professores e o trabalho baseado em desafios intermodulares exigem tempo para o planejamento, para o trabalho contínuo dos alunos e alunas em diferentes atividades, para que os espaços também sejam repensados e acomodados às novas formas de se trabalhar. Junto a isso, a autogestão do EDC significa que a própria equipe de docentes pode adaptar - de acordo com as necessidades que surgem - os horários dos alunos, que podem organizar espaços de trabalho de forma flexível etc.

\section{Avaliação por competências orientada para a evolução das pessoas e o desenvolvimento de sua aprendizagem}

As mudanças que estão sendo propostas dificilmente serão consolidadas, se não for dada atenção especial à avaliação, adaptando seu foco e sua prática à nova abordagem desenvolvida nas salas de aula de EP. Uma visão ampla, de acordo com as abordagens educacionais atuais, coloca a avaliação como outra ferramenta a serviço da aprendizagem; por isso, fala-se de avaliação como evolução para/no desenvolvimento das competências - técnicas e transversais - das pessoas. Nesse sentido, o acompanhamento do aluno, a sua tutorização e a contribuição do feedback correspondente - tanto individual quanto em grupo - são aspectos fundamentais para o progresso e a melhoria progressiva na formação dos(as) alunos(as). Tudo isso é favorecido com uma plataforma de computador específica - Skills Evolution Tool (SET), projetada para essa finalidade.

\subsection{Desenvolvimento do modelo ETHAZI nos Centros EP}

O desenvolvimento do modelo ETHAZI nos Centros EP do País Basco foi concretizado a partir de uma estrutura ou organização que na gestão empresarial é chamada de "mancha de óleo". Inicialmente, a equipe de coordenadores da Tknika começou formando um pequeno grupo de docentes, a maioria dos quais - ao mesmo tempo em que já trabalhavam com metodologias ativas em suas salas de aula - iam posteriormente adquirindo funções de acompanhamento e formação de docentes, tanto do próprio Centro como de outros centros que incorporavam o modelo em seus Ciclos de Formação.

Desde que o trabalho foi iniciado nesse modelo com cinco Centros EP, a filiação a ele tem sido de caráter voluntário, tanto para os docentes quanto para os próprios Centros. A fim de ampliar o conhecimento e a aplicação do modelo ETHAZI, a formação tem sido oferecida anualmente a todos os docentes da EP do País Basco, com um primeiro nível, básico, orientado para aspectos do trabalho em equipe, comunicação e aprendizagem baseada em projetos; e um segundo nível, o mais difundido, que se concentra no desenvolvimento de: Fundamentos da Aprendizagem Colaborativa, Aprendizagem Colaborativa Baseada em Desafios e 
Avaliação por Competências. Embora, como já foi apontado, a participação tenha sido voluntária, a inscrição nos cursos de formação deve ter a aprovação da Direção do Centro de origem do docente; isso é feito com um duplo propósito, por um lado, para propósitos organizacionais e/ou administrativos do próprio centro, e, por outro, para envolver progressivamente a direção dos centros no apoio e aplicação do modelo ETHAZI.

Paralelamente, foi oferecido - normalmente, para pessoas que haviam completado a proposta de formação mencionada anteriormente em um curso anterior - uma formação de um nível diferente no intuito de gerar o que é chamado de Coordenadores de Aprendizagem. Essa é uma figura, também apoiada e endossada pela Direção do Centro (muitas vezes, é parte integrante de tal direção), cuja finalidade é atuar como líder da mudança metodológica no Centro, para o qual essa formação Ihe fornecerá competências de liderança e gestão de pessoas, competência em métodos e técnicas de aprendizagem e competências em gestão de projetos a médio e longo prazo.

Essas formações, em ambos os níveis, além dos aspectos mencionados, também incorporam temas relacionados à criatividade; propostas para a dinamização da aprendizagem - que culminam com o programa UrratsBat para a criação de empresas por parte dos alunos deEP -;e, mais recentemente, com o desenvolvimento da Educação em Valores, com base na proposta Valores 4.0 para a EP da Euskadi.

Ao longo dos anos, alguns desses coordenadores de aprendizagem vêm assumindo funções de mais alto nível e responsabilidade, uma vez que são considerados - com base em sua experiência em sala de aula e no Centro - impulsionadores e facilitadores do trabalho de/em outros Centros. Dessa forma, consolidam-se pequenas redes de 5 a 8 Centros que têm como referência esses docentes, os quais, por sua vez, são coordenados periódica e sistematicamente com a equipe da Tknika.

De forma complementar a todos os itens anteriores, eventos (in)formativos são realizados com os Diretores dos Centros, bem como com os responsáveis pela Inspeção Educacional. Este último é essencial para harmonizar - e compatibilizar com os regulamentos existentes - as novas formas de programação e trabalho em sala de aula, que derivam da aplicação dessa nova proposta educacional; ao mesmo tempo, é um trabalho que deve continuar a ser realizado nos próximos anos, enquanto os Projetos Curriculares existentes são revisados e atualizados com as pessoas responsáveis por eles no Instituto Vasco del Conocimiento de la Formación Profesional (IVAC).

A formação e o envolvimento dos docentes são o aspecto crucial sobre o qual novos modos de ação podem ser desenvolvidos em sala de aula - sendo essencial e complementar ao exposto anteriormente, o apoio e incentivo da Direção dos centros e da Inspeção Educacional. Por essa razão, juntamente com os diferentes cursos de formação, e entendendo que o objetivo é colocar em prática na sala de aula, a partir da Tknika - contando com o apoio de pessoas experientes nessas tarefas - é feito um acompanhamento de todos e cada um dos Centros, organizando-se jornadas de trabalho com Diretores e Coordenadores de Aprendizagem. 
Ao mesmo tempo e como suporte instrumental de livre-acesso para todos os professores de EP, existe um repositório digital que está sendo construído e consolidado com as contribuições de toda a comunidade educacional. Esse repositório digital oferece apoio às equipes docentes nos seguintes aspectos:

- Contexto. Nesta seção, há uma breve introdução ao modelo, suas origens e sua estrutura didático-metodológica.

- Competências digitais. Sem maiores delongas, deve-se notar que uma figura semelhante à do Coordenador de Aprendizagem está sendo criada nos Centros EP, que é o do Pedagogo TIC, cuja função é dinamizar - de acordo com o Marco Europeu de Competências Digitais (também dinâmico e em evolução) - o desenvolvimento de competências digitais nesses níveis educacionais. Portanto, nesta seção, os docentes encontram - além da definição e do nivelamento de tais competências digitais - ideias, propostas e atividades para trabalhá-las no desenvolvimento das diferentes fases ou momentos de um desafio.

- Aprendizagem colaborativa. Nesta seção, os docentes encontram, juntamente com aspectos de natureza mais teórica (já trabalhados por eles em alguns dos cursos que fizeram), ideias e ferramentas para desenvolver a aprendizagem colaborativa, criar equipes com diferentes técnicas, ideias do que pode ser um desafio de introdução a essa maneira de trabalhar.

- Desafios. Como nas seções anteriores, além de uma apresentação do tema em questão - neste caso, o que se entende por desafio e quais são suas principais características - existem formatos em suas duas modalidades: professores e alunos. Uma importância crescente será a aquisição do Banco de Desafios na Instituição e que se consolida com as contribuições dos diferentes Ciclos e Centros EP do País Basco.

- Competências e avaliação. Um dos principais aspectos do modelo ETHAZI é que tem como referência o desenvolvimento de competências técnicas e transversais, tornando necessário identificá-las. As competências técnicas (e os resultados de aprendizagem associados a elas) são estabelecidas pelo projeto curricular básico de cada ciclo. Por sua vez, as competências transversais devem ser definidas por cada um dos Centros; a fım de facilitar este trabalho - mas sem intenção de imposição - da Tknika, são apresentados aqueles que, ao longo destes anos, se consolidaram como mais necessários no entorno. Então, nesta seção se pode encontrar tanto a descrição quanto o nivelamento baseado em rubricas - dessas competências transversais.

Como indicado anteriormente, outro dos aspectos-chave da mudança educacional é a abordagem que é feita da avaliação. Nesta seção, pode-se consultar o Guia para Avaliação, Feedback e Qualificação no Trabalho por Desafios ETHAZI. Esse é um documento esclarecedor, de ajuda e aberto à melhoria e contribuições da comunidade educativa de Formação Profissional do País Basco. 
Para facilitar a nova abordagem à avaliação - focada na evolução dos(as) alunos(as) para a realização de competências - existe também uma ferramenta de computador que oferece múltiplas possibilidades de trabalho e consulta para alunos e docentes. Esta ferramenta, denominada Skills Evolution Tool (SET), não é de domínio público, embora todos os Centros EP tenham acesso a ela e, atualmente, muitos deles já realizem os processos de avaliação, monitoramento, feedback e qualificação a partir dela.

Da mesma forma, nesta seção há um infográfico dinâmico que permite visualizar de maneira sintética e divertida múltiplos aspectos para cada uma das etapas que, genericamente, são desenvolvidas ao longo de um Desafio (Figura 10).

\section{Figura 10 - Infográfico dinâmico para apoiar o desenvolvimento de um desafio}
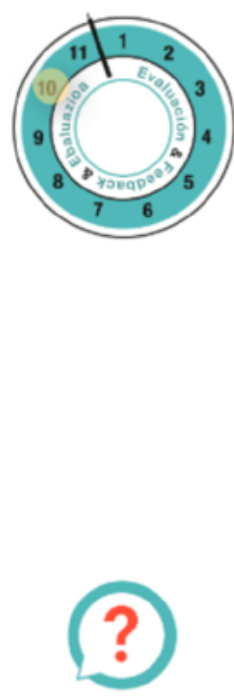

(1)

\section{EXPOR RESULTADO}

TIPO DE TRABALHO

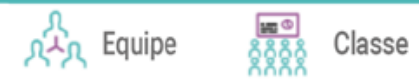

$\Omega$ Individual

\section{FERRAMENTAS}

Uso das TICs

\section{COMPETÊNCIASTRANSVERSAIS}

Colaboradores (trabalho em equipe)

Comunicação (oral, escrita)

Digital (criação de conteúdos, solução de

problemas)

\section{FERRAMENTAS TIC}

Prezi / Slidehare / Powtoon / Glogster

/ Canva / Blogger / Wix / Wordpress

\section{AVALIAÇĀO}

Coavaliação da exposição por aula: 3 ideias, 2 dúvidas (veja fase 10 do desafio de localização) Avaliação de professores (perguntas preparadas): coletar evidências (para seguir a rubrica) Diário reflexivo

Portfólio: tempo para coletar dados e prepará-lo para apresentar ao corpo docente (deixando em aberto a parte de avaliação e comprometimento).

Fonte: Tknika.

- eNOLA. Nesse repositório está em permanente construção, com as contribuições de toda a comunidade educativa da EP do País Basco, também uma ferramenta de autodiagnóstico para as equipes docentes de cada Ciclo (eNOLA). Essa ferramenta busca incentivar a reflexão de cada equipe docente sobre o nível de implementação desse modelo em seus Ciclos de Formação correspondentes, o que é continuado com o desenho de planos de melhoria.

Por sua vez, do ponto de vista sistêmico, os resultados dos diagnósticos oferecem a possibilidade de decidir sobre as linhas de ação a serem implementadas em cada curso, uma vez que essa ferramenta oferece informações sobre cinco áreas:

- Aprendizagem colaborativa baseada em desafios

- Programação baseada em desafios intermodulares. 
- Avaliação por competências orientadas para a evolução.

- Equipes de docentes autogeridas.

- Flexibilidade organizacional.

De forma quantitativa, a Figura 11 mostra a evolução na implementação desse modelo ao longo dos últimos cinco anos escolares, o que reflete claramente a convicção dos Centros EP do País Basco pela inovação e mudança em suas salas de aula.

Figura 11 - Evolução do programa ETHAZI. Centros e Ciclos participantes (eixo esquerdo) / Alunos e professores envolvidos (eixo direito)

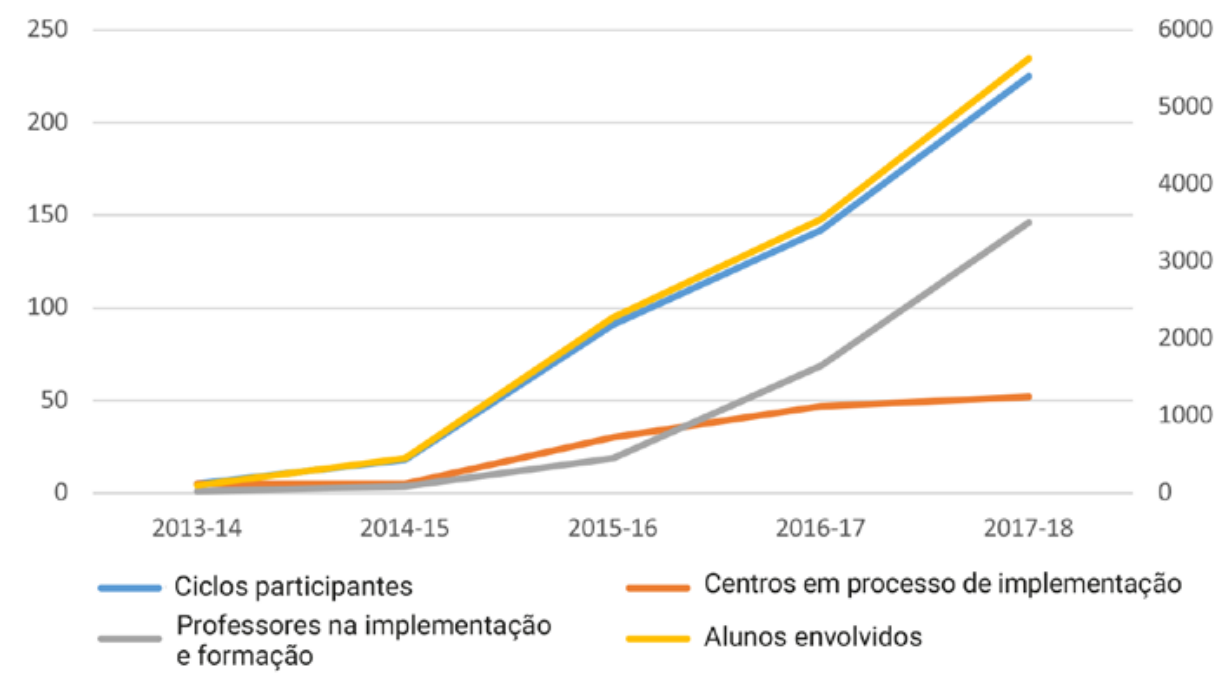

Fonte: Elaboração própria.

\section{Considerações finais}

Atualmente, o modelo ETHAZI proposto para a EP do País Basco apresenta-se como ferramenta útil que - por meio da mudança metodológica - procura responder às mudanças que estão ocorrendo nos níveis trabalhista, tecnológico e social.

Neste contexto, é necessário continuar com a generalização do modelo ETHAZI para todos os Centros EP do País Basco; com a avaliação e monitoramento dos impactos que, em diferentes níveis, a aplicação desse modelo exerce nos Centros de EP; a geração e/ou adaptação dos desafios de acordo com as particularidades de cada ciclo de formação e dos grupos de alunos que neles trabalharão, tendo sempre como horizonte o ambiente de trabalho; o contraste com as empresas para a validação e o aprimoramento do modelo, a fim de responder às suas diversas demandas; e a socialização e avaliação dos resultados e conclusões da implementação do modelo ETHAZI.

Embora a ferramenta de autodiagnóstico ainda seja uma novidade para os Centros, entre os dados obtidos nas autoavaliações realizadas, foi possível perceber que as equipes docentes de 35\% dos ciclos ofertados na EP do País Basco vêm realizando 
A maioria das equipes docentes modificou e expandiu sua perspectiva de avaliação suas avaliações de autodiagnóstico. Nesses ciclos, a programação baseada em desafios intermodulares é altamente desenvolvida e, de acordo com o exposto, a aprendizagem colaborativa baseada em desafios é uma realidade na maioria dos centros que realizaram o autodiagnóstico. Além disso, a maioria das equipes docentes modificou e expandiu sua perspectiva de avaliação e está focada na área de avaliação orientada para a evolução.

De tudo isso, conclui-se que é importante trabalhar em três linhas de ação:

a. Aprofundar na aplicação da qualidade do modelo ETHAZI em todos os Centros EP do País Basco, com especial ênfase no perfil do corpo docente, bem como nas ajudas e formação exigidas para a implementação satisfatória do modelo.

b. Analisar a influência de outros aspectos (espaços, recursos, organização...) no desenvolvimento do modelo ETHAZI, aplicando as melhorias que podem resultar em sua maior qualidade.

c. Avaliar o impacto e a repercussão desse modelo de formação nas novas necessidades apresentadas pelas empresas, adaptando-as de acordo com os resultados obtidos.

d. Reforçar a investigação para melhorar a Formação Profissional no País Basco, com base nas práticas e realidades existentes, promovendo o desenvolvimento de competências técnicas e competências transversais.

\section{Notas}

${ }^{1}$ De uma perspectiva histórica e cultural, também serão encontradas referências ao País Basco (Euskal Herria, em idioma basco) com um âmbito geográfico mais extenso, que inclui a Comunidade Foral de Navarra (no estado espanhol) e as províncias bascas do sudoeste francês (Lapurdi, Baixa Navarra, Zuberoa).

${ }^{2}$ Ao longo do texto, será usado para se referir às diferentes pessoas ou profissões que são mencionadas, acima de tudo, o genérico professor, docente ou aluno, e deve ser entendido que se refere ao gênero masculino e feminino.

${ }^{3}$ Alguns antecedentes que levaram tanto à criação da Tknika quanto à mudança pela qual a EP do País Basco passou nos últimos anos estão refletidos em Intxausti et al. (1999). Da mesma forma, os primeiros trabalhos que são mencionados neste artigo, e que constituem o início do atual modelo educacional, podem ser vistos em Astigarraga, Agirre e Carrera (2017).

${ }^{4}$ A maior parte da formação inicial na EP é organizada com base em Ciclos de dois anos de duração. Os de Nível Médio dão continuidade ao Ensino Secundário Obrigatório; os de Nível Superior, são estudados depois do Bacharelado. O Sistema Educacional como um todo pode ser graficamente visualizado aqui. 
${ }^{5}$ Além disso, comumente sob o mesmo nome, às vezes é feita referência à estratégia metodológica, enquanto, em outras ocasiões, fala-se sobre a metodologia concreta.

${ }^{6}$ Ver, a título de exemplo: Johnson et al. (2009), Apple (2010), Instituto Tecnológico y de Estudios Superiores de Monterrey (2015).

${ }^{7}$ Aqui estão indicados aqueles que, a priori, seriam ideais; dependendo do contexto, do nível educacional, da experiência dos alunos no desenvolvimento desse tipo de trabalho, do momento do curso, do assunto a ser abordado, do tempo disponível... essas condições são diferenciadas e contextualizadas pela equipe docente.

${ }^{8}$ Como exemplo de tudo isso, pode ser visto: https://www.youtube.com/watch? $\mathrm{v}=u 90 \mathrm{KadUVLjs}$ ou de forma um pouco mais ampla: https://www.youtube.com/watch?v=CusOD9Wdilg\&t=310s

\section{Referências}

ADEGI. Observatorio de empleo de Gipuzkoa, $\mathbf{n}$. 10: evolución del nivel formativo de la población activa vasca e inserción laboral de jóvenes según nivel y tipo de formación. San Sebastián, 2016. Disponível em: <https://www.adegi.es/adegi/ observatorio-empleo-gipuzkoa-n10-evolucion-nivel-formativo-poblacion-activavasca-insercion-laboral-jovenes-segun-nivel-tipo-formacion-201608/>. Acesso em: 18 out. 2018.

APPLE. Challenge based learning: a classroom guide. [S.I.], 2010. Disponível em: $<$ https://images.apple.com/education/docs/CBL_Classroom_Guide_Jan_2011. pdf>. Acesso em: 18 out. 2018.

ASTIGARRAGA, E.; AGIRRE, A.; CARRERA, X. Innovación y cambio en la formación profesional del País Vasco: el modelo ETHAZI. Revista Iberoamericana de Educación, v. 74, n. 1, p. 55-82, 2017. Disponível em: <https://rieoei.org/RIE/issue/ view/50>. Acesso em: 18 out. 2018.

AUTOR, D. H.; DORN, D. The growth of low-skill service jobs and the polarization of the US Labor Market. American Economic Review, v. 103, n. 5, p. 1553-1597, 2013. Disponível em: <https://www.ddorn.net/papers/Autor-Dorn-LowSkillServicesPolarization.pdf>. Acesso em: 18 out. 2018.

\section{BANCO INTERAMERICANO DE DESARROLLO. Competencias del siglo XXI en}

Latinoamérica. Washington, DC, 2016. Disponível em: <http://www.iadb.org/ es/temas/educacion/competencias-del-siglo-xxi-en-latinoamerica,3130.html>. Acesso em: 18 out. 2018. 
BARKLEY, E. F.; CROSS, K. P.; MAJOR, C. H. Técnicas de aprendizaje colaborativo. Madrid: Morata, 2012.

BARRON, B.; DARLING-HAMMOND, L. Perspectives et défis des méthodes d'apprentissage par investigation. Em: BARRON, B.; DARLING-HAMMOND, L. Comment apprend-on?: la recherche au service de la pratique, Paris: OCDE, 2010. cap. 9, p. 213-240.

CEDEFOP. Application of learning outcomes approaches across Europe: a comparative study. Luxembourg: Publications Office of the European Union, 2016. Disponível em: <http://www.cedefop.europa.eu/files/3074_en.pdf>. Acesso em: 18 out. 2018.

CEDEFOP. Defining, writing and applying learning outcomes: a European handbook. Luxembourg: Office for Official Publications of the European Communities, 2017. Disponível em: <http://www.cedefop.europa.eu/files/4156_ en.pdf>. Acesso em: 18 out. 2018.

CEDEFOP. Learning outcomes approaches in VET curricula: A comparative analysis of nine European countries. Luxembourg: Publications Office of the European Union, 2010. Disponível em: <http://www.cedefop.europa.eu/files/5506_ en.pdf>. Acesso em: 18 out. 2018.

CEDEFOP. Menos fuerza bruta y más cerebro para los trabajadores del futuro. Nota Informativa, Luxembourg, jun. 2018. Disponível em: <http://www.cedefop. europa.eu/files/9130_es.pdf>. Acesso em: 18 out. 2018.

CEDEFOP. The shift to learning outcomes: conceptual, political and practical developments in Europe. Luxembourg: Office for Official Publications of the European Communities, 2009. Disponível em: <http://www.cedefop.europa.eu/ files/4079_en.pdf>. Acesso em: 18 out. 2018.

COMISIÓN EUROPEA. Comunicación de la Comisión al Parlamento Europeo, al Consejo, al Comité Económico y Social Europeo y al Comité de las Regiones: nuevas prioridades para la cooperación europea en educación y formación. Bruselas, 26 ago. 2015. Disponível em: <http://eur-lex.europa.eu/legal-content/ES/ TXT/PDF/?uri=CELEX:52015DC0408\&rid=4>. Acesso em: 18 out. 2018.

COMISIÓN EUROPEA. Regional innovation scoreboard. Bruselas, 2016. Disponível em: <http://ec.europa.eu/growth/industry/innovation/facts-figures/regional_en>. Acesso em: 18 out. 2018. 
CONFEBASK. Necesidades de empleo y cualificaciones de las empresas vascas para 2018. [S.I], 2018. Disponível em: <http://www.confebask.es/sites/default/ files/noticias/2018-04/Encuesta-Empleo-y-Cualificaciones-2018.pdf>. Acesso em: 18 out. 2018.

CONSEJO ECONÓMICO Y SOCIAL VASCO. La empleabilidad de la juventud de la CAPV y el acceso al mercado laboral desde una perspectiva regional europea comparada. Bilbao: CES, 2018. (Colección de estudios e informes, n. 14). Disponível em: <http://www.cesegab.com/Portals/0/Libros/ESTUDIO\%2014.pdf>. Acesso em: 18 out. 2018.

ELLIOT, S. W. Computers and the future of skill demand. París: OCDE, 2017.

INSTITUTO TECNOLÓGICO Y DE ESTUDIOS SUPERIORES DE MONTERREY. Aprendizaje colaborativo. Monterrey: ITESM, 1999. Disponível em: <http://sitios. itesm.mx/va/diie/tecnicasdidacticas/3.htm>. Acesso em: 18 out. 2018.

INSTITUTO TECNOLÓGICO Y DE ESTUDIOS SUPERIORES DE MONTERREY. Reporte EduTrends: aprendizaje basado en retos. Monterrey: ITESM, 2015. Disponível em: <http://observatorio.itesm.mx/edutrendsabr/>. Acesso em: 18 out. 2018.

INTXAUSTI, K. et al. Nuestro viaje a la calidad. Usurbil: Iceberg-Taldeka, 1999.

JOHNSON, L. F. et al. Challenge-based learning: an approach for our time. Austin, Texas: The New Media Consortium, 2009.

LOSHKAREVA, E. et al. Skills of the future: how to trive in the complex new world. [S.I.]: Global Education Future: World Skills Russia: Future Skills, 2018. Disponível em: <http://edu2035.org/images/people/WSdoklad_12_okt_eng-ilovepdfcompressed.pdf>. Acesso em: 18 out. 2018.

MENÉNDEZ VELÁZQUEZ, A. Historia del futuro: tecnologías que cambiarán nuestras vidas. Oviedo: Ediciones Nobel, 2017.

ORGANIZACIÓN PARA LA COOPERACIÓN Y EL DESARROLLO ECONÓMICO. Innovative learning environments. Paris: OCDE, 2013.

ORGANIZACIÓN PARA LA COOPERACIÓN Y EL DESARROLLO ECONÓMICO. Skills for social progress: the power of social and emotional skills, OECD skills studies. París: OCDE, 2015. 
UNIÓN EUROPEA. El marco europeo de cualificaciones para el aprendizaje permanente (EQF-MEC). Luxemburgo: Oficina de Publicaciones Oficiales de las Comunidades Europeas, 2009. Disponível em: <https://ec.europa.eu/ploteus/sites/ eac-eqf/files/broch_es.pdf>. Acesso em: 18 out. 2018.

WORLD ECONOMIC FORUM. New vision for education: unlocking the potential of technology. Geneva: WEF, 2015. Disponível em: <http://www3.weforum.org/docs/ WEFUSA_NewVisionforEducation_Report2015.pdf>. Acesso em: 18 out. 2018.

WORLD ECONOMIC FORUM The future of jobs: employment, skills and workforce strategy for the Fourth Industrial Revolution. Geneva: WEF, 2016. Disponível em: <http://www.weforum.org/reports/the-future-of-jobs>. Acesso em: 18 out. 2018. 